Scottigh Tradition $\mathcal{Y} 0 \mathrm{l} .221997$

\title{
Sentiment ANd Community
}

n contemporary political philosophy, the view that groups, and not just individuals, have rights and that the authenticity of individuals within those groups is directly dependent upon their rootedness in and identification with their culture has been eagerly embraced by many. For the purposes of this article, I will follow David Bromwich in identifying this belief as "culturalism" and those who defend it as "culturalists." According to Bromwich, "[c]ulturalism is the thesis that there is a universal human need to belong to a culture - to belong, that is, to a selfconscious group with a known history, a group that by preserving and transmitting its customs, memories, and common practices confers the primary pigment of individual identity on the persons it comprehends." 1

Culture, here, is ordinarily understood to have a distinctly ethnic resonance, although the definition of a cultural group need not be limited in this way. ${ }^{2}$ In Canada, of course, culturalist arguments have been invoked mainly to advance the cause of Quebec nationalism, aboriginal rights and bureaucratic multiculturalism. ${ }^{3}$ Curiously overlooked in these discussions, however, has been the case of the Cape Breton Gael. I propose to focus on this neglected case, but only 
in order to try to expose the failings of culturalism.

On Cape Breton Island - and in Highland strongholds on the Nova Scotia mainland, like Antigonish one can detect intermittent stirrings of the same sort of ethnic triumphalism that pervades Quebec. Though a decidedly runtier mutation, the Cape Breton strain shares many of the attractions of its Quebec counterpart, as well as many of its shortcomings: the ready inclination to distinguish between one's own stereotypically idealized kind and all stereotypically diminished outsiders; a tolerance, even appetite, for the fatuous, hypocritical and the palpably third-rate, as long as it is one's "own"; the habit of construing criticisms from without as "attacks" and criticisms from within as "betrayals."

Culturalists assume that ethnic and other group affiliations constitute an indispensable source of value, that culturally distinct practices and histories are unqualifiedly ennobling. My own, very different view, is that a preoccupation with culture can contribute as much to smugness, apathy, self-romance and stuntedness as to nobility, that it can deflect one from greater, more honest and more challenging purposes. The success of culturalism, I further suspect, is attributable above all to its habit of sentimentalizing groups, their histories and the very notion of cultural belonging. Culturalism represents an effort to psychologize politics. It is indeed a political therapeutic, sparing those whom it presumes to defend from the brute facts of existence and eliding ambiguity in the service of blessed simplicity. 


\section{Scottish Tradition $\mathfrak{Y o l . 2 2} 1997$}

Sentimentality is a concept that begs for clarification. Not only does it account for much that is sloppy and shallow in public debate, but it is symptomatic of current fashions in irrationality that repudiate the critical, in favour of the feeling, mind. To begin our own enquiry, let's consider the following stray remarks. In 1785 , one Henry MacKenzie wrote: "In morals as in religion there are not wanting instances of refined sentimentalists who are contented with talking of virtues which they never practice, who pay in words what they owe in actions." 4

John Galsworthy observed that " $[\mathrm{t}]$ he value of a sentiment is the amount of sacrifice you are prepared to make for it," implying that a sentiment, or genuine feeling, is bound to decline into sentimentality if it costs the person who experiences it little or nothing.

In J.D. Salinger's Raise High the Roofbeam, Carpenters, the narrator invokes R.H. Blyth's definition of sentimentality. According to Blyth, "we are being sentimental when we give to a thing more tenderness than God gives it." 5 More recently, the Nobel laureate, Seamus Heaney, has written that, though pleased to have come upon an anthology of Irish Gaelic poetry published in 1981, the encounter yet made him aware how much of his "sense of the tradition had remained a sentiment rather than a possession acquired 'by great labour'." 6

This theme of the cost of emotions and the sentimentalist's failure to pay in kind comes up again, and indeed finds its clearest expression, in Oscar Wilde's 


\section{Scottish Tradition YOol.22 1997}

frequently cited recrimination of Lord Alfred Douglass. Wilde wrote: "The fact is that you were, and are I suppose still, a typical sentimentalist. For a sentimentalist is simply one who desires to have the luxury of an emotion without paying for it. You think that one can have one's emotions for nothing. One cannot." 7 Commenting on Wilde, Michael Tanner ventures that "a dominant element in sentimentality is that the feelings which constitute it are in some important way unearned, being had on the cheap, come by too easily, .... All these charges are part and parcel of the allegation that to be sentimental is to be shallow in a specially noteworthy way."

Sentimentality, it seems, is not so much a particular kind, but rather a particular mode, of feeling or thought. ${ }^{9}$ One is sentimental, that is, not by experiencing an emotion called "sentimentality," but rather by experiencing any number of emotions or states of mind in a certain way; namely, lazily, conveniently, selectively, self-indulgently. Now, upon what does the culturalist, or cultural sentimentalist, direct his self-aggrandizing gaze? How does his sentimentality manifest itself?

Consider the following remarks by Archibald A. MacKenzie in an appendix to his History of Christmas Island, in which he reviews the characteristics of the pioneers of Christmas Island Parish, Cape Breton.

The pioneers who settled Christmas Island Parish were men who possessed many good qualities which their descendants of the present generation should ponder over and 


\section{Scottish Tradition YOol.22 1997}

try to emulate. In the first place, they were men of courage and strong will. This is proved by the fact that though they had their wives and families to provide for, yet they did not hesitate to leave their homes in their bonnie, native glens to go on board crowded, unsanitary, old-fashioned sailing ships to cross the stormy Atlantic, and come to a country where, as they knew, the severity of winter was extreme, where there were no houses to shelter them and but small prospect of food to sustain them; in short, where there was nothing but the forest primeval extending to the water's edge.... The succeeding generation were good representatives of their sturdy ancestors. There were no drones among them.... In short, our forefathers were steady workers. They led frugal, abstemious lives; and their wants were few and easily supplied, hence the good measure of prosperity and comfort which they enjoyed.... Our forefathers were charitable to one another.... They were optimistic by nature. In spite of the many disappointments, trials and tribulations that beset their paths, they always looked on the bright side of life and hoped for the best. They lived near to God and trusted in His goodness to provide for their temporal and spiritual wants. Hence their cheerfulness on all occasions. ${ }^{10}$ 


\section{Scottigh Tradition $\mathcal{Y o l . 2 2} 1997$}

Now, I have no wish to dishonour the memory of these settlers, the courage, perseverance and goodness of many of them, nor do I wish to impugn the efforts of MacKenzie himself, who, after all, was intending only to offer a breezy eulogy more than any kind of critical assessment. Still, the picture he presents to us here is an idealization - the Highlander was courageous; the Highlander always worked hard; the Highlander was always cheerful. Thus, he sentimentalizes his subject. But he also encourages a sentimental appreciation of his subject on the part of others. Indeed, the fierce or comforting pride that a Cape Breton Gael might feel upon reading such a passage is a good example of the sort of unearned emotion that Wilde and company abhor. And it is unearned not just because it is prompted by an obviously selective review of the facts, but also because it concerns the labours, qualities and achievements of others, without requiring that the person who purports to admire these virtues manifest them in his own life.

Charles W. Dunn's Highland Settler is marginally more critical, if only because he deals openly with charges that the Highlander was "ignorant and lazy" and "perfectly indifferent about education." 11 Still, his assessment of Highland vices is glib, his attempted defences of them awkward and evasive. For instance, to the charge of laziness, he half-heartedly and with unintentional comedy, counters: "The Highlander was... more of an artist than a labourer..."12 Throughout, Dunn's tone is cloyingly elegiac, his sweeping generalizations gaudily sentimental. We learn from him that the Cape 


\section{Scottish Tradition YOol.22 1997}

Breton Gael is independent of spirit, fiery of temperament, that he is respectful of inherited wisdom, stern in his piety and warm in his human affections. He proclaims "the true Gael" one who is "devoted to religion, clanship and love." 13 Referring to Jonathan G. MacKinnon, a champion of Gaelic earlier this century, he remarks: "Typically a Gael, he was deeply devoted to the island where he was born." ${ }^{14}$ of the settlers generally, he says, "[t]hey would not have been truly Gaels if they had not felt pangs of separation when they parted from the scenes of their childhood," adding later that "they still retain a feeling of individuality, a love for their own traditions, and a memory of their own unique origin." 15

What originates in a conception of one's people as noble victims, accelerates to the point where that people is portrayed as unambiguously, almost enchantingly, virtuous. One is reminded here of Robert Fulford's remarks on the subject of what he calls "victim art". In such art, he complains, the response is self-contained. In other words, a work or production is cute, it tells you that it's cute, and it tells you to regard it as cute. It is immensely manipulative, then. Fittingly, where responses are thus pre-determined, one is spared of labour. So the response is in a sense very much unearned.

What goes for art goes for histories and reminiscences. It would be pleasing to regard oneself as, by nature, a bard and a brave warrior, but to accept this self-portrayal would be to fall prey to the bewitchingly simplistic entreaties of the sentimentalist - and, indeed, to become a sentimentalist oneself. Dunn writes as if 


\section{Scottigh Tradition $\mathcal{Y o l . 2 2 ~} 1997$}

the virtues of loyalty and courage, love for one's people and one's land were special possessions of the Highland Scot, a view so sweepingly general and so obviously applicable to so many who are not Highland Scots, as well as inapplicable to many who are, that it is, not so much untrue, as utterly uninterested in the truth.

The realism I am urging does not require that we forsake all sentiments and ideals. One can indeed express realistic sentiments and embrace realistic ideals. But these invariably prove both complex and demanding. They encourage reflection and self-scrutiny, confronting us with paradox and ambiguity, the sort of difficulties that demand a resolution that can never be complete. Sentimental ideals, however, are founded upon artificially neat distinctions, stock characterizations, clammy cliché, manipulating our emotions, intellects and imaginations, without exercising them.

The demand for recognition and respect of, and reward for, one's ethnicity or tribal history proceeds from a curiously passive form of self-regard. ${ }^{16}$ That I am of Scottish descent, of Highland descent, a MacKinnon, a Catholic, a Canadian is due to nothing at all that I, as an individual, have done. In an article entitled, "The Sentimental Self," Joseph Kupfer writes: "The trite, cliché, and stock entrench the familiar past, the appreciation of which requires only that we recognize the type, and the well-worn emotional path is readied to be walked again." 17 Regardless of the immediate object of sentimentality - dogs or people, a country or a tribal past - "its resting place," says Kupfer, "is always the 


\section{Scottish Tradition YOol.22 1997}

self." 18 And the sentimental self, so averse to challenge and difficulty, will not grow.

In his book, Blood and Belonging, Michael Ignatieff cites an example that nicely illustrates Kupfer's claim. Ignatieff devotes an entire section of his concluding chapter to a 74 year old Ulsterman, named Tommy Doyle. He writes:

What it means to be British for Tommy is essentially what it means to be Protestant. The two cannot be distinguished,.... Orangeism is his life because both of his loyalties, to the Crown and to his religion, are united in the Orange creed. It is what makes Tommy a happy man; he knows who he is and that he is doing God's work. But it also means he is a man who cannot change or learn. ${ }^{19}$

We could even say that to define oneself in terms of Crown and creed, or of a people and its past, is to declare oneself a culturalist. But whereas the culturalist favours abstract categories borrowed from the social sciences to account for identity, Bromwich urges instead what he calls a "novelistic" approach. An individual's identity, he says, is not reducible to class, race, ethnicity, religion and gender. Rather, it is more like a temperament, infinitely subtle and complex. ${ }^{20}$

Here is an example of what I think Bromwich has in mind. In Richard Ford's novel, Independence Day 


\section{Scottish Tradition YOol.22 1997}

the main character, Frank Bascombe, wonders about a friend of his ex-wife's, an eye doctor named Henry Burris:

My problem is only that I don't know where to attach my own eyes to Henry, can't sense him, and not even that I can't tell you what makes him tick. Eyes make him tick: how you fix 'em, what's wrong with 'em.... But what I can't tell, ... is what and where his mystery is, the part you'd discover if you knew him for years, learned to respect him professionally.... What are his uncertainties, the quality of his peace made with contingency, his worries about the inevitability of joy or tragedy out in the unknown where we all plow the seas: his rationale, based on experience, for the advisability of discretion?21

Bascombe's is a meditation on the sorts of subtleties of character that make a man who he is. Not all allegiances are pre-determined, but rather acquired, supplemented and refined. Roundedness of character, and all the complexity and nuance it entails, is an ideal in life as in literature, and identity a matter as much of achievement and chance as it is of inheritance.

John E. MacKinnon

Saint Mary's University 